\title{
Standardization and Development: Brief Discussion on Chinese Quick Transaction Mechanism of Minor Criminal Case
}

\author{
Jingchao Zhao ${ }^{1}$ \\ ${ }^{1}$ China University of Political Science and Law, Law school, 2014 grade Ph. D Candidate, Beijing, China \\ Correspondence: Jingchao Zhao, No.25 Xitucheng Road, Graduate School of China University of Political \\ Science and Law, Haidian District, Beijing100088, China Tel: 86-1358-2222-8281. E-mail: \\ huadianlw@sina.com
}

Received: October 6, 2015 Accepted: October 21, 2015 Online Published: November 29, 2015

doi:10.5539/jpl.v8n4p277 URL: http://dx.doi.org/10.5539/jpl.v8n4p277

\begin{abstract}
At present, establishment of diversified Chinese quick transaction mechanism of minor criminal case has become an important project that the judicial organ have to confront due to the reason that the simple procedure set up by Criminal Law of our country is not efficient for transacting the increasing minor criminal cases. Since 2014, Standing Committee of the National People's Congress has authorized the Supreme People's Court and the Supreme People's Procuratorate to launch reform of quick transaction mechanism of minor criminal case in 14 cities like Beijing according to the overall scheme of Central judicial system reform. Since the reform, Courts around have begun to focus on protecting the lawful rights and interests of the criminal suspect and the defendant when they are establishing quick verdict program of minor criminal cases so as to ensure the justice of the case, of which useful experience has been taken.

But from the perspective of judicial practice, judicial process of places is not unified because more principled rules of quick transaction mechanism of minor criminal case are launched only by the Supreme People's Court and the Supreme People's Procuratorate. Many problems occur in practice: application and scope are not inconsistent; time is too long in handle procedures before trial, which will influence efficiency; cooperation of public security unit, the inspecting authorities, and courts are not efficient; evidence system of minor criminal cases is not perfect..... These problems have restricted the function of quick transaction mechanism. Therefore, quick transaction mechanism of minor criminal case is to be standardized.
\end{abstract}

Keywords:minor criminal case, standardization, development, court decision

\section{Origin of Problems}

At present, establishment of diversified Chinese quick transaction mechanism ofminor criminal case has become an important project that the judicial organ have to confront due to the reason that the simple procedure set up by Criminal Law of our country is not efficient for transacting the increasing minor criminal cases. Since 2014, Standing Committee of the National People's Congress has authorized the Supreme People's Court and the Supreme People's Procuratorate to launch reform of quick transaction mechanism of minor criminal case in 14 cities like Beijing according totheoverallscheme of Central judicial system reform. Since the reform, Courts around have begun to focus on protecting the lawful rights and interests of the criminal suspect and the defendant when they are establishing quick verdict program of minor criminal cases so as to ensure the justice of the case, of which useful experience has been taken.

Since the Supreme People's Court and the Supreme People's Procuratorate have been authorized by Standing Committee of the National People's Congress to go on reform pilot, they have launched Opinions about Quick Transaction Mechanism of Minor Criminal Case. Courts around the country have also explored and issued relevant implementation details on the basis of the Opinion. On the whole, applicable scope of quick transaction mechanism is limited to those cases which meet the following four conditions: the first condition is that these cases are featured with simple case, clear facts, as well as certain and sufficient evidence; second is that the criminal suspects may be sentenced to three years imprisonment, criminal detention, surveillance, and single fine; third is that the defendant and his counsel have no objection to the facts and charges against the accused, and they are voluntary to confession; the final condition is that applicable law has no controversy. 
But from the perspective of judicial practice, judicial process of places is not unified because more principled rules of quick transaction mechanism of minor criminal case are launched only by the Supreme People's Court and the Supreme People's Procuratorate. Many problems occur in practice: application and scope are not inconsistent; time is too long in handle procedures before trial, which will influence efficiency; cooperation of public security unit, the inspecting authorities, and courts are not efficient; evidence system ofminor criminal cases is not perfect..... These problems have restricted the function of quick transaction mechanism. Therefore, quick transaction mechanism of minor criminal case is to be standardized.

After modification of the system of reeducation through labor, the original objects of reeducation through labor must accept decentralized treatment of administrativization and criminality. And especially those who are divided into minor criminal cases should be handled efficiently and properly. In current judicial practice, the problem of how to regulate the original objects of reeducation through labor normatively via quick transaction mechanism of minor criminal case must be defined.

\section{Problems Existing in our country's Transaction Mechanism of Minor Criminal Case}

\subsection{The Public Security Organs Have not Yet Been Incorporated into Quick Transaction Mechanism of Minor Criminal Case}

From the perspective of efficiency, the implementation of quick transaction mechanism is based on the normative documents issued by the Supreme People's Court and the Supreme People's Procuratorate, which focus on making principled simplification of criminal procedure such as arrest, prosecution, and trial so as to save judicial resources and improve efficiency of transacting minor criminal case. But handling criminal cases asks integrated coordination among public security organs, procuratorial organs, and courts, and the coordinated action of the judicial organs is needed to achieve quick transaction of minor criminal case. In the current reform pilot practice, effects of quick transaction of minor criminal case are not obvious in some areas for the reason that guidelines issued by the Supreme People's Court and the Supreme People's Procuratorate are rather principled, and that these guidelines lack detailed division and definition of public security organs' responsibility during investigation procedure. For example, in some areas implementation of quick transaction mechanism of minor criminal case is promoted by public security organs, procuratorial organs, and courts through joint conference and documents that are signed jointly, but the mechanism cannot be operated effectively due to lack of legal sanction and constraint, which lead to the result that the mechanism is just limited on the working mechanism level and the three organs cannot connect with each other efficiently, thus causing mechanism fault.

\subsection{Reform Pilots around the Country Lacks Unified Standard}

From the content of the system, there are only 12 principles in the Opinion launched by the Supreme People's Court and the Supreme People's Procuratorate, though these principles have elaborated on scope of application, time limit of trials, and management principle of the mechanism, most of them are general principles without unified standard of application of the mechanism, which makes the mechanism have strong casualness of application, to be more influenced by human factors( Zhang Xiaoling,2003),and lack essential operability. Rules for the implementation, which are made by local judicial organs, are carried out differently by different areas, and investigators may reach a verdict with great subjectivity. Both of the problems cause the result that the mechanism's scope of application is not normative, and that the mechanism's effects are weakened. For instance, the Opinions issued by the Supreme People's Court and the Supreme People's Procuratorate has elaborated on time limit of trials about those cases that is applied to quick transaction mechanism ofminor criminal case, requiring procuratorial organs to make decisions on those criminal cases about whether to approve arrest and prosecute within 2 days and 20 days respectively, which reflects the feature of quick transaction of minor criminal cases. But the norm that which kind of case should be included in quick transaction mechanism is still unclear, thus causing inconsistent norms in practice in different areas, and the situation, in which investigators will deny quick transaction mechanism though the case is applied to the mechanism, may even come up under the stress of too much cases yet few staff.

\subsection{Simple Scope of Application and Lack of Operability}

Rigid understanding occurs in the process of implementing quick transaction mechanism of minor criminal case. There are two purposes of building the mechanism: one is to improve lawsuit efficiency as restricted judicial resources will be concentrated on handling important, difficult, and complex cases through quick transaction of minor criminal case. The other is to implement the policy of temper justice with mercy so as to relieve social contradiction timely and reduce disharmonious factors. In 2010, revise of the rule of criminal reconciliation and non-prosecution with conditions made by Criminal Law reflects the legislation trend that quick transaction of minor criminal case is becoming mitigative and humanitarian. But in the process of implementing the Opinion 
issued by the Supreme People's Court and the Supreme People's Procuratorate, rigid stipulation of time limit of trials causes aspiration of quick operation. Practice that including as many cases in lawsuit as possible via quick arrest and quick trial lead to the result that in some cases with little subjective malignancy such as light injury, traffic accident, and under-age crime, prosecutors, among whom reconciliation may be achieved, are forced to give up the opportunity of reconciliation by communication. This is a violation of the original intention of the mechanism.

Moreover, there is stipulate in the Opinion that quick transaction mechanism of minor criminal case is applied to those simple criminal cases with clear facts, in which the criminal suspects may be sentenced to three years imprisonment, criminal detention, surveillance, and single fine, and they are voluntary to confession. At the same time, the applicable law has no controversy. It can be said that the scope of applied cases, which is stipulated by the Opinion, is still limited, and there are too many restricted conditions, which makes it difficult for the quick transaction mechanism of minor criminal case to play a role of acceleration. On the other hand, stipulation of application scope in the Opinion is general and principled with no enumeration of charge conditions, which brings difficulty and challenge to case selectors in judicial practice. For example, prison terms of some cases in specific provisions of criminal law are not limited to three years but five to seven years, so whether suspects of these cases may be sentenced less than three years is a problem for accurate conclusion will be made after advanced judgement of comprehensive case and law enforcement environment.

\section{OverseasExamples of Quick Transaction Mechanism of Minor Criminal Case}

Our country is not the first when it comes to exploration of quick transaction mechanism of minor criminal case. Both Anglo - American law system countries and continental legal system countries have actually made practice exploration of improving lawsuit efficiency in legislation for a long time. Overseas exploration of quick transaction mechanism of minor criminal case can be divided into two types.

One transaction pattern is combination of public security trial and simple confession trial which is represented by America. U.S. federal rules of criminal procedure have made clear stipulation of quick transaction mechanism of minor criminal case. There is clear stipulation in the second rule:"this rule aims to provide stipulation for handling every criminal charge correctly so as to ensure simplification and justice of judicial procedure, thus further avoid unnecessary cost and delay." Under guidance of this rule, America divides minor criminal cases into two kinds: magistrate trial and judex ordinarius. Suspects in obvious minor criminal cases are told to plead guilty in investigation stage, and then these cases will be heard quickly by magistrate. General criminal suspects can be released on bail by paying low bail, and the trial process will not influence suspects' normal life and work. There are Arraignment procedures before trial in those minor criminal cases that is tried by judex ordinarius, that is if defendants make plea of guilty, it will means that they have given up a series of constitutional rights such as against self -incrimination, fair jury trial, confrontation with witnesses against themselves, and summon of his own witness. Therefore, guilty plea of those cases is result of plea bargain. (Joshua Dressler, Michaels C Alan.,2009)

In Britain, minor criminal cases are always being processed according to classification of crimes. Principled minor criminal cases will be tried by magistration court, indictable offences will be tried by criminal court, and as to ambiguous crimes, defendants can choose either magistration court or criminal court to try. The magistration court can only sentence imprisonment under 6 months and fine less than 5000 pounds (Splat John,2006)); while in cases tried by criminal court, the judge should make measurement of penalty in possible time if defendants plead guilty.

The other transaction pattern is simplified handling mode of minor criminal cases that is represented by Germany. Germany added the 153rd "a" when it revised Code of Criminal Procedure in 1975. Thus in the case of the judge and the defendant's consent, procurators are authorized to determine the legal consequences of a crime in the form of written punishment order without trial by court according to the written application for misdemeanor prosecutors, which is called Verfahren bei Strafbefehlen. The Verfahren bei Strafbefehlen in German's CodeofCriminalProcedure also has the nature of plea bargaining. In addition, transaction efficiency is improved by taking the form of plea bargaining in Germany judicial practice. In recent twenty years, defendants, prosecutors, and judges can reach an agreement on find guilty and measurement of penalty at all stages of the procedure in German criminal procedure. The reached agreement not only has effect on the decision and judgement made by procuratorate and court, but in some sense, has concrete manipulation of the decision and judgement. (Xiong Qiuhong, 2014)

France and Italy have similar system besides German. Among them, The Criminal Procedure Code of France has set up a fixed penalty procedure, summary procedure, and summary procedure in the case that the defendant 
appeared in court under the condition of pleading guilty in advance. The Criminal Procedure Code of Italy has also set up summary procedure, in which applicable criminal punishment can be made in accordance with the client's requirements, thus cases may be tried quickly or even be tried immediately. Japan, our neighboring country, has learned from the experience of the continental lagal system of minor criminal cases. Article 1 of criminal procedure law of japan has ruled: the purpose of this law is to maintain public welfare and protect basic human rights in criminal cases, and at the same time, to find the truth of the case so as to achieve accurate and rapid application of the Penal Decree. In Japan, cases that are simple or have clear evidence should be tried by court immediately. Procuratorate applies for judgement in summary procedure in the form of written or spoken, yet in summary procedure, punishment against freedom that is more than 1 year or rectification and security should not be sentenced.

Improving the efficiency of litigation gives a rational basis for setting up a quick simple judgement procedure in criminal proceedings, and it has become a principle of consensus. But as to the problem of how to embody it via simplified discrete of criminal procedure, different countries and places have different ways. From the practical experience of different countries, quick transaction mechanism of minor criminal case should include the whole process of criminal procedure, especially investigation stage; quick transaction mechanism of minor criminal case should also have characters of clear and flexible application scope, effective duration reduction, and simplification of procedure.

\section{Normative Assumption of Quick Transaction Mechanism of Minor Criminal Case}

1) Division of labor cooperation, and abbreviation of the time limit of pre-trial. At present, quick transaction mechanism of minor criminal case is limited to procuratorate and court, and is also limited to case review and prosecution as well as case trial process. Yet in judicial practice, what takes up the longest time in criminal case handling is the stage before case review and prosecution. Those cases with slight circumstance and clear facts especially take up more time because criminal suspects of these cases are always freed on bail pending an appeal. After awaiting trial on bail, it will take a lot of time from investigation stage to the stage of review and prosecution, which will not only occupy a large amount of judicial resources, but also bring difficulties to complete resolve of minor criminal cases. Therefore, quick transaction mechanism of minor criminal case should make a clear division of labor among public security unit, inspecting organs, and courts in the process of handling minor criminal cases, and should also make the time limit of handling cases clear for public security unit in particular. As to those cases that have clear facts and little arguments and that the suspects have pleaded guilty, public security unit should transfer review prosecution as soon as possible so as to reduce the influence of pretrial on case handling time.

2) Exploration of the mechanism of special appeal to the minor criminal cases to improve application efficiency. From the perspective of judicial practice, minor criminal cases, ordinary criminal cases, or complex criminal cases may be mixed to deal with by procuratorate and courts in the process of handling minor criminal cases due to the reason that rules of the Opinion are too principled and that different understandings of the problem that whether some cases are applied to quick transaction mechanism ofminor criminal case exist inevitably in practice. When such problem occurs, it will take at least one or two weekdays to judge, so a uniform scale of minor criminal cases' application is necessary. Therefore, on the basis of the classification of cases, further exploration of the mechanism of special appeal to the minor criminal cases is necessary. Cases that can be judged as minor criminal cases in investigation stage should directly go to the light criminal case review and prosecution of procuratorate, and then they should be tried in unified court by court light criminal cases rapid trial departments; cases that are difficult to judge whether they are applied to quick transaction mechanism of minor criminal case by the investigation organ should be reviewed by the procuratorial organs: if they are applied after the review, they will be concluded by court light punishment case trial departments; if not, they will be reviewed and prosecuted as general criminal cases.

3) Strengthening the protection of the rights of the parties to avoid the abuse of mechanism. Quick transaction of minor criminal case is at the price of sacrificing some litigation rights of the criminal suspects and the defendants, but it should have the prerequisite that the defendant's rights of knowing information and defense are not simplified. Some systems and procedures for the design of minor criminal cases in foreign countries are used on the basis of the parties' choice or consent, which has protected the parties' right of free choice of judgement mode and further realized procedural justice. And as the results are recognized by the parties, probability of appeal is reduced, which objectively saves judicial resources and improves litigation efficiency. The mechanism design of the present stage of our country does not give the accused enough right of lawsuit participation and the right of procedure option. Simultaneously, what the mechanism solves is to deliver the suspect and defendant to trial more quickly, and as the mechanism focuses on protecting the defendant's litigation rights and interests, the 
victim's right of relief is easy to be ignored. As to minor criminal cases that have victims, the victims' right to learn the truth should be strengthened, and their opinions and suggestions should be listened to before reaching an agreement or judgment. Before trial, the criminal suspects as well as defendants should as possible be impelled to compensate for the loss the victims suffered so as to reach a criminal settlement, speed up the handling of cases, and safeguard the victims' legitimate rights and interests.

4) Further reducing the duration and simplifying the process to improve the application effect of the mechanism. Duration of quick transaction mechanism of minor criminal case should be prescribed on the basis of comprehensive consideration of judicial practice and scientific calculation of the time and work load of the contractors. There should be further prescription that cases which meet the condition of quick transaction should not be lingeringly reported or be returned to the supplementary investigation. Once situations that do not meet the condition of quick transaction occur during the process of investigation, quick transaction procedure should be terminated, and the cases should be turned into a common procedure. In the preliminary ideas of perfecting quick transaction mechanism of minor criminal case, there are still a lot to be improved. We should actively explore ways and means of innovating mechanism in the system level and operational level within the existing legal framework, and improve the efficiency of handling cases on the basis of ensuring the quality of the case, and shorten the period of proceedings so as to maximum effectiveness of the mechanism.

5) Improving assessment, rewards, and punishment mechanism, as well as improving the applicability of the mechanism. Scientific and reasonable evaluation system is conducive to the promotion of criminal judicial organs and regulations, ensuring the quality of case, and improving the efficiency of handling cases. Judicial organs can explore an evaluation system that can reconcile both justice and efficiency by reforming performance appraisal system: one is to establish individual law enforcement archives system. Situations of quick transaction of minor criminal case should be subsumed into assessment scope, and are taken as one of the content of performance appraisal of the annual work, hooking up with management evaluation. The other is to reduce the role of digital indicators in the performance evaluation considering the complexity and diversity of the judiciary.(Wu Dun, Zhou Zhao,2014)Investigators' working quality of case handling and case handling efficiency should be inspected and evaluated through periodic supervision and examination of the mechanism's application for them so as to enhance their awareness of working quality and effect of case handling and to ensure the long-term stable operation of the mechanism. Meanwhile, concept of case handling and judicial style of transactors who handle mechanism transformation cases should be inspected via reform. Cases of which criminal reconciliation is reached for the purpose of mitigation of punishment and decriminalization of treatment should be subsumed into main assessment as points index so as to establish effective administrative incentive mechanism and inspire the enthusiasm as well as initiative of the investigators. Establishment of punishment mechanism should also be explored. Judicial functionary who do not use quick transaction mechanism if the mechanism is applied to the case and do not conclude trial in accordance with the provisions of the law case handling period will be prosecuted.

6) To further clarify the scope of application so as to avoid the rigidity of the work. According to article-208th of Criminal Procedure, the applicable scope of summary judgment procedure is revised and expanded, that is the summary trial procedure is applied to those cases which have clear facts and abundant proof, and of which defendants confess to his crimes and have no objection to the facts of the crime as well as the summary procedure. It can be seen that the application of the summary trial procedure is no longer limited by the sentence. While in June 2014, pilot criminal quick decision procedure of the Supreme People's Court and the Supreme People's Procuratorate which is authorized by Standing Committee of the National People's Congress provides the applicable scope and condition: the applied cases are those that have clear facts and abundant proof, and of which defendants confess to his crimes and the parties have no objection to the applied law, such as dangerous driving, traffic accidents, theft, deceit, rob, harm, and causing disturbances. And these cases all have light circumstances, and the suspects may be sentenced to one year imprisonment, criminal detention, control or fines.

\section{Conclusion}

The same point of quick transaction mechanism, summary procedure, and the arbitration procedure is that they are all set up to simplify the handling procedures; the differences of them are that summary procedure and the arbitration procedure are mainly in the trial process, while quick transaction mechanism relates to all aspects, namely detection, arrest, prosecution, and trial, and it has wider application as it includes the application of summary procedure, and the arbitration procedure. Under the guidance of this, the scope of application of the quick transaction mechanism of minor criminal case can have appropriate readjustment according to that of summary procedure and the arbitration procedure, but the mechanism's scope should not be limited to this scope. Therefore, it is appropriate to define the scope of the mechanism for less than three years' set term of 
imprisonment. On the one hand, considering that the original intention and the name of the mechanism are to define minor criminal cases, it is obviously wrong to extend applicable crime to capital felony if we refer to summary judgement procedure. On the other hand, criminal law sentencing of a considerable amount of charges standards in three years as boundaries, which to a certain extent is beneficial to case diversion. On the basis of this, cases with high frequency of application in practice should be cited based on the pilot experience, such as theft, dangerous driving, drug trafficking, intentional injury, traffic accidents, swindle, rob, causing disturbances, casinos, credit card fraud, holding drugs unlawfully. As to those cases, operation standards and law enforcement should be unified. Since circumstances that are not suitable for the mechanism like defendants' withdrawal of a confession and changes of the facts may occur in the process of handling, reasons for terminating the mechanism should be clear and exit mechanism should be set so as to make sure the availability of the case. Simultaneously, as to some cases that do not meet the conditions of transaction mechanism, prescription can be cleared in the mechanism by combining the revise of summary procedure. Felony cases that flagrant delicts and defendants plead guilty and that have sufficient evidence can be transacted quickly by referring to the procedure so as to be applied to the light and slow criminal policy in the maximum range, and improve litigation efficiency.

\section{References}

Dressler,J., \& Alan,M. C. (2009). Understanding Criminal Procedure(Second volume criminal trial), Wei Xiaona(trans). Beijing: Peiking University Press, 167-168.

Wu, D., \&Zhou. Z. (2014). Preliminary Study on the Rapid Procedure of Minor Criminal Cases. Journal of Law Application, (8).

Xiong, Q. H. (2014). The Protection and System Construction of the Criminal Summary Procedure. Beijing: People's procuratorial semimonthly, (14).

Xu, M. J., \&Yang, L. T. (Trans). (2006). Splat John. Emmins on Criminal Procedure. Beijing: China Renmin UP, 119-120, 348-349.

Zhang, X. L. (2003). Procedure Diversion in Criminal Procedure. Political and legal forum, (2).

\section{Copyrights}

Copyright for this articleis retained by the author(s), with first publication rights granted to the journal.

This is an open-access article distributed under the terms and conditions of the CreativeCommons Attribution license (http://creativecommons.org/licenses/by/3.0/). 